\title{
REPORT OF THE AMS SAMPLE PREPARATION WORKSHOP SATURDAY 13 AUGUST 1994
}

\author{
JOHN S. VOGEL
}

\section{Center for Accelerator Mass Spectrometry, Box 808, L-397, Lawrence Livermore National Laboratory, University of California, Livermore, California 94550 USA}

The AMS Sample Preparation Workshop was held on Saturday afternoon 13 August and was attended by $30-40$ scientists. Four abstracts were submitted for presentation, two concerning pollen separation from sediments and peats, one on graphitization of small pollen samples, and one on graphite behavior in a high-intensity ion source. This led to the organization of the workshop into a first half on sample pretreatment and definition, with the second half divided into progress on graphitization and
graphite performance.

Despite the two organized presentations about pollen, I urged the participants to comment on preparation of samples such as bone, rocks and ice, which had been lively points of discussion at previous conferences. The urging was in vain, as participants reported that these were now routine processes requiring no new discussion. In particular, various laboratories continue to use different processing to separate bone fractions (mainly collagen) for dating, but all agree that only "good" bones are accepted for measurement. The implication is that badly degraded bone cannot successfully be treated to obtain a fraction that gives a trustworthy age. The University of California at Riverside group, however, is still pursuing osteocalcin as a suitable material for extraction from degraded bones. A comment on textile measurement warned that standard cellulose extraction might be too harsh for linen and that pitch or wax are contaminants that are difficult to separate from linen, but can be detected under microscopic scrutiny. (A caution about dating textiles that have been stored behind altars with beeswax candles might be in order?) The attendees engaged in sampling, e.g., ice, rocks and atmospheric particles, agreed that their sciences could progress only if better backgrounds and precisions could be obtained for samples under $100 \mu \mathrm{g}$, with $10 \mu \mathrm{g}$ being a desirable sample size.

The sample-size argument was also made strongly by the three participants who presented pollen dating procedures. As presented during the conference, Thomas Brown introduces sieving and strong sulfuric acid washes to a procedure similar to normal palynological preparation. His research uses the larger pine pollens from the North Pacific coast of North America, and exceptionally clean pollen in quantities up to $1 \mathrm{mg}$ are obtained. His process works well for the large quantities of large pollens $(20-80 \mu \mathrm{m})$ that are available in lake sediments. Richardson and Hall (1994), on the other hand, separate small flower and grass pollens from peat sediments by flocculation with household disinfectant and slow microbial destruction of non-pollen fractions. The microbes are those readily available for adding to household septic disposal systems. Jürg Hauenstein compared several pollen purification methods, including the "standard" palynological approach and Brown's approach, using small aliquots of a single sediment. Unfortunately, the dates he obtained from these small (20-100 $\mu \mathrm{g})$ isolates were widely discordant by up to thousands of years, with no obvious trend suggesting either an old or a young contaminant. Hauenstein presented his graphitization procedures for the workshop's scrutiny, but these did not appear to explain the variations. The workshop participants concluded that the ability of pollen to withstand extreme treatment procedures probably indicates a long residence time within many matrices, making it possible that very small samples of pollen might actually reflect disparate ages. This workshop, then, cautioned submitters to be sure that they could uniformly define a very small sample before obtaining an age for it. The other conclusion from the first half of the workshop was (to all the AMSers' delight) that palynologists and other 
users should be more responsible for defining the sample they want dated, and that AMS labs should not be expected to provide a date for anything other than the sample that was submitted.

Jürg Hauenstein's presentation directly led to a discussion about making graphite from small samples of combusted $\mathrm{CO}_{2}$. In general, smaller reaction volumes $(s 1 \mathrm{ml})$ and higher temperatures $(>600$ $700^{\circ} \mathrm{C}$ ) (to produce a higher pressure?) are required to precipitate the graphite in a reasonable time on/in the iron. At lower temperatures and larger volumes, samples $<100 \mu \mathrm{g}$ may require several more hours to reduce to graphite than larger samples. Michael Verkouteren presented his method to process small $(s 10 \mu \mathrm{g})$ samples into graphite using an iron wool catalyst and manganese chips as the reductant. The simplicity of the arrangement allows a very small volume, and iron/carbon is easily separated from the manganese magnetically. He obtained $80 \%$ completion in a number of samples and documented low $(\leq 2 \%)$ isotope fractionation in samples that progress to $>75-80 \%$ complete. If the reaction is halted at lower completion, the fractionation seen with this reductant is similar to that quoted for zinc reduction (Jull et al. 1986), and hydrogen reduction (Vogel, Southon and Nelson 1987). Neither of these studies shows a fractionation versus completion plot, but the plots were presented at conferences and correspond reasonably well to that shown by Verkouteren (ms.) and to the plots of fractionation versus completion from batch processing approaches of Kitigawa et al. (1993) and Vogel (1992). For finished samples, many, including McNichol et al. (1992) and Bonani et al. (1987) report final-sample or AMS-measured fractionations of $2 \%$ or less. None of these others, of course, had demonstrated the low fractionation that Verkouteren shows for samples as small at $10 \mu \mathrm{g}$. It is possible that the $2 \%$ fractionation seen when samples are nearly complete is a function of the $\mathrm{CO}-\mathrm{Fe}$ reaction and is independent of the $\mathrm{CO}_{2}-\mathrm{CO}$ reduction by zinc, hydrogen or manganese.

Once the fractionation of a processing procedure is known, the next most important factor is the contamination or background introduced by the process. It was agreed that all labs should try to keep data on their backgrounds (quantified using combusted coal, hydrolyzed calcite or tank $\mathrm{CO}_{2}$ ) as functions of sample size, particularly for sample sizes under $500 \mu \mathrm{g}$. A plot from Kirner, Taylor and Southon (1995) was used as an example. The plot implied that a nearly constant amount of 1-1.5 $\mu \mathrm{g}$ of Modern-equivalent (M-e) carbon had contaminated the small samples. This is half of what Vogel, Nelson and Southon (1987) reported for combustion in Vycor, and is equal to what they found for combustion in Pyrex. John Southon (personal communication 1994) similarly reports a 1.5-2 $\mu \mathrm{g} \mathrm{M-e} \mathrm{for} \mathrm{the}$ several graphite production lines used at Lawrence Livermore National Laboratory. Others show similar levels of 1-3.5 $\mu \mathrm{g}$ M-e contamination (e.g., Wilson 1992; Jull, Donahue and Toolin 1990). Only a large amount of data for each laboratory will be able to show if, indeed, the processing background arises from a constant source of contemporary carbon, and in what stage of processing that contamination is introduced.

The final discussion involved data shown by the chairman indicating that the "high intensity" ion sources with hemispherical ionizers could, in fact, produce final 1-3\%o precision and accuracy using $80-120 \mu \mathrm{A}$ beams of $\mathrm{C}^{-}$. Samples are recessed graphite on iron/cobalt and become pitted during the 2-h measurements. The isotope ratio changes only a few percent when the cesium beam sputters through the sample, and an as-yet undetermined correction depending on current could provide high precisions and accuracies in even shorter times.

The workshop concluded that new directions of AMS measurements demanded reliable sample preparation methods for samples $<100 \mu \mathrm{g}$. Catalytic reduction of $\mathrm{CO}_{2}$ to graphite on iron remains the accepted way to introduce carbon samples in a sputter source, but sample pretreatment is still not so easily specified, especially for the newest material for chronology: pollen. The palynologists may lead the way in AMS sample preparation, however, in insisting that the submitting scientist take a 
more active role in defining the sample that is to be dated, rather than rely on the recently acquired and suspect skills of a physicist at the AMS laboratory!

\section{ACKNOWLEDGMENTS}

The Chairperson thanks the participants for the lively afternoon discussion, and especially thanks Brian Miller for being the local Workshop organizer whose preparation made the afternoon progress so well.

\section{REFERENCES}

Bonani, G., Beer, J., Hoffman, H., Synal, H. A., Suter, M., Wölfi, W., Pfleiderer, C., Kromer, B., Junghans, C. and Münnich, K. O. 1987 Fractionation, precision and accuracy in ${ }^{14} \mathrm{C}$ and ${ }^{13} \mathrm{C}$ measurements. Nuclear Instruments and Methods in Physics Research B29: 87-90.

Jull, A. J. T., Donahue, D. J., Hatheway, A. L., Linnick, T. W. and Toolin, L. J. 1986 Production of graphite targets by deposition from $\mathrm{CO} / \mathrm{H}_{2}$ for precision accelerator ${ }^{14} \mathrm{C}$ measurements. In Stuiver, M. and Kra, R. S., eds., Proceedings of the 12 th International ${ }^{14} \mathrm{C}$ Conference. Radiocarbon 28(2A): 191-197.

Jull, A. J. T., Donahue, D. J. and Toolin, L. J. 1990 Discussion: Recovery from tracer contamination in AMS sample preparation. Radiocarbon 32(1): 84-85.

Kirner, D., Taylor, R. E. and Southon, J. R. 1995 Reduction in backgrounds of microsamples for AMS radiocarbon dating. Radiocarbon, this issue.

Kitigawa, H., Masuzawa, T., Nakamura, T. and Matsumoto, E. 1993 A batch preparation method for graphite targets with low background for AMS ${ }^{14} \mathrm{C}$ measurements. Radiocarbon 35(2): 295-300.

McNichol, A. P., Gagnon, A. R., Jones, G. A. and Osborne, E. A. 1992 Illumination of a black box: Analysis of gas composition during graphite target preparation. In Long, A. and Kra, R. S., eds., Proceedings of the 14 th International ${ }^{14} \mathrm{C}$ Conference. Radiocarbon 34(3): 321-329.

Richardson, F. and Hall, V. A. 1994 Pollen concentrate preparation from highly organic Holocene peat and lake deposits for AMS dating. Radiocarbon 36(3): 407-412.

Verkouteren, R. M. (ms.) Batch production of microchemical AMS targets. Paper presented at the 15th International ${ }^{14} \mathrm{C}$ Conference, Glasgow, Scotland, 15-19 August 1994.

Vogel, J. S. 1992 Rapid production of graphite without contamination for biomedical AMS. In Long, A. L. and Kra, R. S., eds., Proceedings of the 14th International ${ }^{14} \mathrm{C}$ Conference. Radiocarbon 34(3): 344-350.

Vogel, J. S., Nelson D. E. and Southon, J. R. $1987{ }^{14} \mathrm{C}$ background levels in an accelerator mass spectrometry system. Radiocarbon 29(3): 323-333.

Vogel, J. S., Southon, J. R. and Nelson, D. E. 1987 Catalyst and binder effects in the use of filamentous graphite for AMS. Nuclear Instruments and Methods in Physics Research B29: 50-56.

Wilson, A. T. 1992 A simple technique for converting $\mathrm{CO}_{2}$ to AMS target graphite. In Long, A. and $\mathrm{Kra}, \mathrm{R}$. S., eds., Proceedings of the 14 th International ${ }^{14} \mathrm{C}$ Conference. Radiocarbon 34(3): 318-320. 